\title{
Efficacy of resuscitative infusion with haemoglobin vesicles for severe postpartum haemorrhage in pregnant rabbits: An animal research study
}

\author{
Hiroki Ishibashi $^{1}$, Kohsuke Hagisawa ${ }^{1}$, Manabu Kinoshita ${ }^{1}$, Yukako Yuki ${ }^{2}$, Morikazu \\ Miyamoto $^{1}$, Hiromi Sakai ${ }^{3}$, Daizoh Saito ${ }^{4}$, Katsuo Terui ${ }^{2}$, and Masashi Takano ${ }^{1}$ \\ ${ }^{1}$ National Defense Medical College \\ ${ }^{2}$ Saitama Medical University \\ ${ }^{3}$ Nara Medical University School of Medicine Graduate School of Medicine \\ ${ }^{4}$ National Defense Medical College Research Institute
}

August 3, 2020

\begin{abstract}
Objective. To investigate the resuscitative efficacy of haemoglobin vesicles (HbVs) for severe postpartum haemorrhage (PPH) using pregnant rabbits. Design: Animal research study Setting: Animal laboratory, National Defense Medical College, Japan Population: Twenty-five female New Zealand white rabbits at late gestation Methods. Pregnant rabbits underwent caesarean section; uncontrolled haemorrhage was induced by transecting the uterine artery to establish a severe PPH model. During the first $30 \mathrm{~min}$ (or until the bleeding volume reached $100 \mathrm{~mL}$ ), all rabbits received $6 \%$ hydroxyethyl starch (HES) infusion. Thereafter, rabbits received any of the three isovolemic fluid resuscitations every 5 min: red blood cells (RBCs) with plateletpoor plasma (RBC/PPP) (vol/vol=1:1, $\mathrm{n}=8), 6 \% \mathrm{HES}(\mathrm{n}=7)$, or HbVs with $25 \%$ human serum albumin $(\mathrm{vol} / \mathrm{vol}=4: 1, \mathrm{n}=10)$. After $60 \mathrm{~min}$ (or when the bleeding volume reached $200 \mathrm{~mL}$ ), we performed surgical haemostasis and monitored the rabbit survival for 12 hours. Main Outcome Measures: Survival time for severe postpartum haemorrhage Results. During the first $30 \mathrm{~min}$, all rabbits showed severe anaemia $(\mathrm{Hb}<6 \mathrm{~g} / \mathrm{dL})$ that eventually developed to severe PPH. All rabbits that received only HES infusion died within 6 hours, whereas those that received RBC/PPP transfusion survived. Furthermore, 8 of the 10 rabbits received $\mathrm{HbV}$ infusion 6 hours after PPH. Overall survival of HbV group was markedly improved compared with that of HES group $(p=0.01)$ but was significantly worse than that of RBC/PPP group $(p<0.01)$. Conclusions. HbV infusion for severe PPH effectively prevented lethal haemorrhagic shock in a pregnant rabbit model, making it a feasible alternative modality.
\end{abstract}

\section{Tweetable abstract:}

Haemoglobin vesicles may be an alternative modality for severe postpartum haemorrhage with unavailable of blood products.

\section{Introduction}

Severe postpartum haemorrhage $(\mathrm{PPH})$ remains the leading cause of maternal morbidity and mortality worldwide $^{1,2}$. In cases requiring blood transfusions, providing adequate blood supply at the earliest time possible is essential. At least $26 \%$ of PPH-related deaths result from a lack of blood transfusion ${ }^{3}$. Blood transfusions are crucial in patients who develop severe PPH. However, access to blood markedly differs between low- and high-income countries.

Regarding initial transfusion therapy for severe PPH, packed red blood cells (RBCs), platelets, and coagulation factors are commonly used. Every obstetric facility should have a plan of comprehensive emergency 
management for $\mathrm{PPH}$, including protocols for accessing packed $\mathrm{RBCs}^{4}$. However, blood transfusion services are highly resource intensive and require voluntary donations, donor screening, including blood-type antigen and cross-matching test, and a temperature-controlled distribution system. Thus, preparing adequate blood transfusion resources at small obstetric facilities is challenging. The spread of epidemics, including the coronavirus disease, further limits the available blood supply for transfusions worldwide ${ }^{5,6}$.

To support the blood donation and transfusion system, haemoglobin (Hb) based oxygen carriers (HBOCs) were developed as blood substitutes for RBC transfusion ${ }^{7}$. Cell-free type HBOCs exert some side effects of bared Hbs, including vasoconstriction, hypertension, and higher frequency of infarction ${ }^{8}$. These results emphasise the significance of mimicking the cellar structure of RBCs to avoid the side effects. Therefore, many studies have attempted encapsulation of Hbs using liposomes to improve their biocompatibility, storage stability, and oxygen-carrying capacity. Accordingly, haemoglobin vesicles (HbVs) as RBC substitutes were developed $^{9,10}$, and the safety of $\mathrm{HbV}$ has been diversified previously ${ }^{11-15}$. HbVs could be useful as a resuscitative fluid for haemorrhagic shock ${ }^{8,16-19}$. Furthermore, HbVs could be stored for at least 1 year; do not need screening, including blood-type antigen or cross-matching test; and have no risk of blood contamination $^{8,18,19}$.

Severe PPH is a type of haemorrhagic shock, and its resuscitative treatment is basically like that for haemorrhagic shock ${ }^{20}$. However, few studies have assessed the efficacy of HBOCs, particularly HbVs, for severe PPH. Moreover, animal models of severe PPH are limited. Yu et al. created an uncontrolled haemorrhagic shock model in pregnant rabbits ${ }^{21}$, but it was not PPH model because this haemorrhage occurred before delivery and did not satisfy the criteria for clinical PPH. This study aimed to investigate the resuscitative efficacy of HbVs for severe PPH resulting to lethal haemorrhagic shock. Towards this goal, we established a severe PPH model using pregnant rabbits based on the actual clinical treatment after delivery.

\section{Methods}

\section{Animal management}

Twenty-five female New Zealand white rabbits at late gestation (gestational age: 28 days, weight: 3.5-3.9 kg; Japan SLC, Hamamatsu, Japan) were used in this study. The rabbits had free access to standard feed and water during a 7-day adaptation period before the experiment. Sixteen male New Zealand white rabbits (weight: 2.6-2.8 kg; Japan SLC, Hamamatsu, Japan) were used as blood donors. Cross-matching between the donor and transfused rabbit was performed to avoid transfusion of incompatible blood types, with strict adherence to the ARRIVE guidelines during the procedure ${ }^{22}$.

\section{Preparation of haemoglobin vesicles}

HbVs were prepared as previously described ${ }^{16,17,23}$. Briefly, Hb was purified from outdated donor human blood provided by the Japanese Red Cross Society. The encapsulated carbonylhemoglobin (HbCO, $38 \mathrm{~g} / \mathrm{dL})$ contained 5.9 mM pyridoxal 5'-phosphate (Sigma Chemical, Saint Louis, USA) as an allosteric effector for regulating oxygen affinity. The lipid bilayer was a mixture of 1,2-dipalmitoyl-sn-glycero-3-phosphatidylcholine; cholesterol; and 1,5-bis-O-hexadecyl-N-succinyl-L-glutamate at a molar ratio of 5:4:0.9 and 1,2-distearoyl-snglycero-3-phosphatidyl-ethanolamine-N-PEG $(0.3 \mathrm{~mol} \%)$. HbV particles were suspended in a physiological salt solution. Nitrogen gas was bubbled through the solution for storage. The properties of $\mathrm{HbV}$ used in this experiment are shown in Table $\mathrm{S} 1$. HbV was sufficiently retained in the blood (half-life: 47-72 hours) ${ }^{24}$. Before the experiments, the $\mathrm{HbV}$ solution was mixed with a $25 \%$ human serum albumin (Benesis, Osaka, Japan) to adjust the albumin concentration of the vesicle-suspension medium to $5 \mathrm{~g} / \mathrm{dL}$. Under these conditions, the colloid osmotic pressure of the suspension was maintained stable at approximately $20 \mathrm{mmHg}^{24}$. $\mathrm{HbVs}$ were stored in deoxygenated glass vials at $4^{\circ} \mathrm{C}$ for at least $10-12$ months and used for all experiments as the $\mathrm{HbV}$ test solution.

\section{Preparation of allogenic RBCs from donor rabbits}

Donor rabbits $(n=16)$ were anaesthetised via intravenous injection of $25 \mathrm{mg} / \mathrm{kg}$ ketamine and $10 \mathrm{mg} / \mathrm{kg}$ xylazine. As described previously, $50 \mathrm{~mL} / \mathrm{kg}$ of donor blood was withdrawn from the femoral artery ${ }^{17}$. After 
removing the platelet-rich plasma and platelet-poor plasma $(\mathrm{PPP})$ from the blood via centrifugation $(100 \times g$ for $15 \mathrm{~min}$ ), the remaining RBCs were washed with acid citrate dextrose solution. Then, the same volume of mannitol adenine phosphate solution (1.457\% [w/v\%] D-mannitol, $0.014 \%$ adenine and $0.094 \%$ sodium dihydrogen phosphate [Terumo, Tokyo, Japan]) was added to prepare allogenic RBCs that were then stored at $4^{\circ} \mathrm{C}$. PPP samples showed the following coagulation activity: fibrinogen, $121 \mathrm{mg} / \mathrm{dL}$; AT III activity, $81 \%$; prothrombin time (PT), $13.1 \mathrm{sec}$; activated partial thromboplastin time (APTT), $31.2 \mathrm{sec}$, on average.

\section{Surgical procedures}

Pregnant rabbits were anaesthetised with ketamine and xylazine followed by intravenous injections of 15 $\mathrm{mg} / \mathrm{kg}$ pentobarbital, and anaesthesia was maintained by additional doses as necessary for the first $30 \mathrm{~min}$ of the experiment ${ }^{23}$. A local anaesthesia of $1 \%$ lidocaine was injected subcutaneously into the left inguinal area and mid-lower abdomen. The adequacy of general anaesthesia was monitored by the loss of the ear pinch reflex. Rabbits were kept supine and spontaneously breathing on the warming plate to maintain the body temperature at $36-37^{\circ} \mathrm{C}$. A 20 -gauge catheter (polyethylene indwelling needle; Terumo, Tokyo, Japan) was aseptically introduced into the left femoral artery for measuring haemodynamics and blood sampling. The same size of the catheter was similarly inserted into the left femoral vein for fluid injections. After instrumentation, rabbits were stabilised for $10 \mathrm{~min}$ to record the baseline data.

\section{Severe postpartum haemorrhage model}

We designed the severe PPH model based on the previous mode ${ }^{21}$ and the actual clinical treatment after delivery. After lower midline laparotomy, we performed caesarean section and delivered foetuses in the right side of the rabbit bicornate uterus (Figure 1A). Thereafter, uncontrolled haemorrhage was induced by transecting the right uterine artery (Figure 1B). The bleeding was wiped off using a high-absorbent gauze (BEMCOT M-1, Asahikasei, Tokyo, Japan), and we counted the absorbed blood volume every 5 min. To compensate the blood loss, an isovolemic infusion of $6 \%$ HES (Voluven 6\%; Fresenius Kabi Deutschland, Bad Homburg, Germany) was repeated every 5 min via the femoral vein until $30 \mathrm{~min}$ or the bleeding volume reached $100 \mathrm{~mL}$. The reason for setting the bleeding volume at $100 \mathrm{~mL}$ is as follows. The need for blood transfusion was determined when the shock index (heart rate/systolic blood pressure) exceeded 1.5 based on a previous study, with a shock index of 1.5 corresponding to a blood loss of approximately $2.5 \mathrm{~L}^{25}$. In pregnant women weighing $60 \mathrm{~kg}$, the circulating blood is approximately $4.6 \mathrm{~L}$, and thus, the blood loss rate in the severe PPH is estimated at approximately $54 \%$ of circulating blood. According to the guidelines of the European Federation of Pharmaceutical Industries Associations and the European Centre for the Validation of Alternative Methods ${ }^{26}$, rabbit circulating blood is estimated at $56 \mathrm{~mL} / \mathrm{kg}$. Considering that the pregnant rabbits weighed about $3.5 \mathrm{~kg}$, the bleeding volume corresponding to severe $\mathrm{PPH}$ was calculated at $106 \mathrm{~mL}$ $(3.5 \mathrm{~kg} \times 56 \mathrm{~mL} / \mathrm{kg} \times 0.54)$. Thus, we set the bleeding volume of severe PPH at $100 \mathrm{~mL}$.

\section{Fluid resuscitation with haemoglobin vesicles, RBCs, or $6 \%$ hydroxyethyl starch}

Following the initial infusion of $6 \%$ HES, rabbits were divided into three groups based on the resuscitation fluid used. All rabbits received isovolemic fluid resuscitation that was equivalent to the bleeding volume every $5 \mathrm{~min}$ until $60 \mathrm{~min}$ or when the bleeding volume reached over $200 \mathrm{~mL}$, which is almost equivalent to the circulation volume in a rabbit ${ }^{26}$. In pregnancy, such a condition is a lethal haemorrhagic shock class $\mathrm{IV}^{27}$. Resuscitative fluid regimens included stored allogenic RBC with PPP (vol/vol=1:1, Hb concentration of $11.9 \pm 1.6 \mathrm{~g} / \mathrm{dL}$ ) (RBC/PPP group, $n=8$ ) as a positive control, $6 \%$ HES infusion (HES group, $n=7$ ) as a negative control, and $\mathrm{HbVs}$ with $25 \%$ human serum albumin ( $\mathrm{vol} / \mathrm{vol}=4: 1, \mathrm{Hb}$ concentration of $8.0 \mathrm{~g} / \mathrm{dL}$ ) (HbV group, $n=10$ ) (Figure 1C). After fluid resuscitation, the rabbits underwent a surgical haemostatic procedure via ligation of bleeding vessels, followed by caesarean section to deliver the foetuses from the left side of the bicornate uterus. Thereafter, the laparotomy incisions were closed, and the rabbits were placed in a cage with laboratory diet and water and monitored for survival for at least $12 \mathrm{~h}$. Postoperative analgesia was performed with intramuscular injections of buprenorphine $(0.02 \mathrm{mg} / \mathrm{kg})$ after $12 \mathrm{~h}$ for euthanasia.

Measurements of blood cell counts, coagulation factors, and blood gases 
Arterial blood samples were obtained every 5 min to count blood cells using an Erma PCE 170 haematology analyser (Erma, Tokyo, Japan). Coagulation factors and blood gases were measured every 15 min. Hb concentration in the blood containing $\mathrm{HbVs}$ could not be accurately determined using the current analyser because liposome capsules interfered with the spectrophotometric measurement of $\mathrm{Hb}$ absorbance. The actual $\mathrm{Hb}$ concentrations were estimated using a previous method ${ }^{17}$. To measure plasma antithrombin (AT) III activity, prothrombin time (PT), and activated partial thromboplastin time (APTT), blood samples were collected into a heparinised syringe and centrifuged at $50,000 \times g$ at $4^{\circ} \mathrm{C}$ for 20 min to remove $\mathrm{HbV}$ particles and were measured at the Sanritsu Zelcova Laboratory (Tokyo, Japan). Plasma fibrinogen levels were measured using rabbit fibrinogen enzyme-linked immunosorbent assay kit (LifeSpan BioSciences, Seattle, USA). Blood gas analyses, including plasma lactate and arterial oxygen content $\left(\mathrm{CtO}_{2}\right)$ levels, were performed using an $\mathrm{ABL}$ 80 blood gas analyser (Radiometer, Copenhagen, Denmark).

\section{Analyses of whole blood coagulation activity}

Coagulation activity of whole blood was measured every 15 min using a coagulation and platelet function analyser (Sonoclot?) (Sienco, Morrison, CO) as previously described ${ }^{22}$. The Sonoclot signal typically describes coagulation parameters including activated clotting time (ACT), which indicates the period up to the start of fibrin formation, and clot rate, which indicates the slope of fibrin gel formation that is affected by both the fibrinogen to fibrin conversion and the amount of fibrinogen.

\section{Analyses of plasma nitric oxide}

Plasma $\mathrm{NO}_{2}{ }^{-} / \mathrm{NO}_{3}{ }^{-}$(nitric oxide, $\mathrm{NO}_{\mathrm{x}}$ ) levels were measured every 15 min. Blood samples were collected in heparin and centrifuged at 50,000 $\mathrm{x} g$ at $4 \mathrm{deg} \mathrm{C}$ for $20 \mathrm{~min}$ to remove $\mathrm{HbV}$ particles. The supernatant was stored at -80 until analysis. Plasma $\mathrm{NO}_{\mathrm{x}}$ levels were measured at the Eicom Laboratory (Eicom Corporation, Kyoto, Japan) using a high-performance liquid chromatography-Griess system, as previously described ${ }^{22}$.

\section{Statistical analysis}

Survival curves were generated using the Kaplan-Meier method, and survival was compared using the logrank test. Statistical comparisons between two groups and among three groups were conducted using Student's t test and one-way analysis of variance, followed by a Bonferroni post hoc test, respectively. Data are presented as mean +- standard deviation (SD). All statistical analyses were performed using JMP 14. software (SAS Institute Inc., Tokyo, Japan). $p$ values $<0.05$ were considered statistically significant. Normality testing was performed using the above statistical analysis.

Based on the hypothesis for the primary study endpoint of survival rates, a sample size calculation was performed using $G^{*}$ Power, version $3^{28}$. The effect size decided to be clinically significant was 0.6. We permitted a type I error of $\alpha=0.05$, and with the alternate hypothesis, the null hypothesis would be retained with a type II error of $\beta=0.2$. Sample size analysis resulted in the need for 30 animals. The final sample size for each group complies with the ARRIVE guidelines ${ }^{22}$.

\section{Results}

\section{Haemodynamic changes and rabbit survival}

The rabbits developed postoperative severe anaemia ( $\mathrm{Hb}$ concentration $<6 \mathrm{~g} / \mathrm{dL}$ ) that progressed to severe $\mathrm{PPH}$ in the first $30 \mathrm{~min}$. There were no significant differences in total haemorrhage volume, time to severe $\mathrm{PPH}$, and total bleeding time among the three groups (Table S2). Although the HES group showed progressively decreased mean arterial pressure (MAP) of less than $40 \mathrm{mmHg}$ at the resuscitative phase, the $\mathrm{HbV}$ and $\mathrm{RBC} / \mathrm{PPP}$ groups maintained MAP above $50 \mathrm{mmHg}$ during this period (Figure 2A). The shock index was also gradually increased until two times higher than that at baseline in the HES group, whereas it was only increased to within 1.5 times higher than that at baseline in the RBC/PPP and $\mathrm{HbV}$ groups (Figure 2B). Within 6 hours, all rabbits in the HES group died, whereas all of the rabbits in the RBC/PPP group survived, and 8 of the 10 rabbits in the $\mathrm{HbV}$ group survived. Regarding overall survival, the prognosis of 
$\mathrm{HbV}$ group was significantly better than that of HES group $(p<0.01)$, whereas it was significantly worse than that of RBC/PPP group $(p=0.01)$ (Figure 3 ).

\section{Haematologic variables}

Administration of $\mathrm{HbVs}$ and RBC/PPP following the initial HES infusion gradually increased Hb concentration, and it was maintained over $6 \mathrm{~g} / \mathrm{dL}$ in both groups, although the Hb concentration decreased under $2 \mathrm{~g} / \mathrm{dL}$ at the end of the experiment in HES group (Figure 3A). In contrast with Hb dynamics, haematocrit (Hct) decrease was similar between $\mathrm{HbV}$ and HES groups, although the Hct level was increased in RBC/PPP group (Figure 3B). HbV particles used in this study did not affect the Hct level because their particle size (particle diameter: 250-280 nm) was extremely small ${ }^{22,29}$. Platelet (PLT) counts could not be measured in $\mathrm{HbV}$ group because the submicron $\mathrm{HbV}$ particle interfered with PLT counting by the current analyser. Meanwhile, the PLT counts gradually decreased in RBC/PPP group but were still significantly higher than those in HES group at the end of the experiment (Figure S1).

\section{Blood gas analyses}

The $\mathrm{pH}$ level was maintained above 7.35 in the $\mathrm{HbV}$ and RBC/PPP groups via respiratory compensation throughout the experiment, whereas the $\mathrm{pH}$ level in the HES group was significantly decreased below 7.35 at 45 and 60 min owing to a lack of haemoglobin $(p<0.01)$ (Figure 3C). There were no significant differences in the base excess levels, the values of $\mathrm{PaO}_{2}$ and $\mathrm{PaCO}_{2}$ among all groups throughout the experiment, indicating that the respiratory function of the animals was well-preserved throughout the experiment (Figure 3D, Figure $\mathrm{S} 2 \mathrm{~A}, \mathrm{~B}$ ). During the initial $30 \mathrm{~min}$, the $\mathrm{CtO}_{2}$ (i.e. the sum of oxygen bound to haemoglobin) decreased to approximately $6.5 \mathrm{vol} \%$ in all the three groups. $\mathrm{RBC}$ transfusion or $\mathrm{HbV}$ infusion restored the $\mathrm{CtO}_{2}$ to 7.0-8.0 vol\% in the $\mathrm{RBC} / \mathrm{PPP}$ and $\mathrm{HbV}$ groups. In contrast, the $\mathrm{CtO}_{2}$ decreased to unmeasurable values at $60 \mathrm{~min}$ in the HES group (Figure 3E). Hence, lactate levels were maintained at approximately $3.0 \mathrm{mmol} / \mathrm{L}$ throughout the experiment in the $\mathrm{HbV}$ and $\mathrm{RBC} / \mathrm{PPP}$ groups, whereas the lactate level in the HES group critically increased to $6 \mathrm{mmol} / \mathrm{L}$ at $60 \mathrm{~min}$, which was significantly higher than that in the other groups $(p$ $<0.05$ ) (Figure 3F). At the end of the experiment, the $\mathrm{HCO}_{3}{ }^{-}$level was higher in $\mathrm{RBC} / \mathrm{PPP}$ group than in the other groups $(p<0.05)$ (Figure $\mathrm{S} 2 \mathrm{C})$.

\section{Coagulation variables and activity and plasma nitric oxide levels}

The plasma fibrinogen levels in RBC/PPP group gradually decreased but was maintained over $110 \mathrm{mg} / \mathrm{dL}$ even at the end of the experiment because PPP contained a certain amount of coagulation factors, including fibrinogen (Figure 4A). In contrast, the plasma fibrinogen levels continuously decreased and reached 20 $\mathrm{mg} / \mathrm{dL}$ in both $\mathrm{HbV}$ and HES groups (Figure 7A). The values of AT III in both HbV and HES groups were significantly shorter than those in $\mathrm{RBC} / \mathrm{PPP}$ group at $45(p<0.05)$ and $60 \mathrm{~min}(p<0.01)$ (Figure 4B). Similarly, the PT was significantly lower in the HbV and HES groups than in the RBC/PPP group at the end of the experiment $(p<0.01)$ (Figure $4 \mathrm{C}$ ). Regarding APTT, the value beyond 30 min was set as reference because the value in over 75 sec could not be measured in this analysis (Figure 4D).

Regarding coagulation activity, ACT was significantly prolonged in both the $\mathrm{HbV}$ and HES groups at the end of experiment compared with that in the RBC/PPP group $(p<0.05)$ (Figure S3A). As for clot rate, all three groups showed similar decreases in the clot rate with no significant differences (Figure S3B). There were also no significant differences in plasma $\mathrm{NO}_{\mathrm{x}}$ levels among the three groups throughout the experiment, and $\mathrm{HbV}$ group showed no significant reduction of $\mathrm{NO}_{\mathrm{x}}$ levels (Figure $\mathrm{S} 3 \mathrm{C}$ ).

\section{Foetus survival after postpartum haemorrhage}

The survival rates of the foetuses after PPH in the left side of the bicornate uterus was $38 \pm 42 \%, 56 \pm$ $49 \%$, and $79 \pm 40 \%$ in HES, HbV group, and RBC/PPP groups, respectively (Table S3). Although there were no significant differences in the foetus survival rate among the three groups, HbV group showed higher survival rates than did HES group but lower than did RBC/PPP group.

\section{Discussion}




\section{Main Findings}

This study developed a severe PPH model after caesarean section using pregnant rabbits. Total haemorrhage was approximately at least $50 \mathrm{~mL} / \mathrm{kg}$ and led to severe PPH that became lethal within a few hours in the absence of any fluid resuscitation. As a result, we established an appropriate animal model requiring massive transfusion according to actual clinical practice. Using the current PPH model, we demonstrated that HbVs helped to maintain haemodynamics for severe PPH. The acute prognosis was better than that achieved with administration of HES, resulting in a drastic reduction of mortality.

\section{Strengths and Limitations}

To our best knowledge, this was the first study to develop initial fluid treatment with HbV infusion for severe $\mathrm{PPH}$. The resuscitative benefit of $\mathrm{HbV}$ treatment in the initial hours led to maintenance of normal lactate levels that in turn resulted in adequate oxygen supply. This indicates that prompt HbV infusion might help stabilise the haemodynamics and enable transport to secondary or tertiary facilities.

Our findings should be interpreted with caution in the context of the principal limitations of the current study. First, the efficacy of $\mathrm{HbVs}$ for severe PPH was evaluated in an animal model, and thus the applicability of the findings in humans need to be further verified. Second, this study did not investigate the long-term safety of HbVs beyond the acute setting. Third, we did not precisely investigate the effects of HbVs on the foetus, including intrauterine resuscitation in this study. A previous study reported the efficacy of HbVs for chronic placental hypoxia and improvement of foetal growth restriction in a rat pre-eclampsia model ${ }^{36}$. However, there are no reports on the efficacy of intrauterine resuscitation of foetuses for low uteroplacental blood flow due to acute massive peripartum haemorrhage, including placental abruption. In this study, the $\mathrm{HbV}$ group showed dilutional coagulopathy due to lack of coagulation factors. Methods for controlling coagulopathy using other blood substitutes with haemostatic capacity, including PLT substitutes ${ }^{23}$ should be further investigated.

Furthermore, this study had methodological limitations. Measurement of systemic $\mathrm{NO}_{\mathrm{x}}$ levels did not always reflect NO metabolism at the cellular levels. Further studies are needed to validate our findings and ultimately establish the use of HbVs for severe PPH in clinical practice.

\section{Interpretation}

RBC and PPP transfusion achieved excellent prognosis and yielded a better foetus survival rate than did HES infusion ( $79 \%$ vs. $38 \%$, on an average), although the difference was not significant. Some animals transfused with RBCs achieved the target $\mathrm{Hb}$ concentration of up to $9 \mathrm{~g} / \mathrm{dL}$ after transfusion for PPH. ${ }^{30,31}$ Consequently, the maternal $\mathrm{CtO}_{2}$ levels reached $>10 \mathrm{vol} \%$, which ensured a foetal $\mathrm{CtO}_{2}$ of 8 vol $\%{ }^{32}$. $\mathrm{HbV}$ infusion also maintained haemodynamic parameters and $\mathrm{CtO}_{2}$ levels to the systemic tissues throughout the experiment. The acute prognosis of the HbV group was significantly better than that of the HES group, whereas it was significantly worse than that of the RBC/PPP group. $\mathrm{HbV}$ infusion yielded a foetus survival rate of $56 \%$. HbVs have a shorter half-life than $\mathrm{RBCs}^{24}$, which might affect the prognosis beyond 6 hours. In addition, carbonic anhydrase is not incorporated into $\mathrm{HbV}$. Consequently, plasma $\mathrm{HCO}_{3}{ }^{-}$levels in the $\mathrm{HbV}$ group was significantly lower than that in the RBC group. This may be critical because some studies reported that low $\mathrm{HCO}_{3}{ }^{-}$, particularly $<16 \mathrm{mmol} / \mathrm{L}$, independently predicted short-term prognosis ${ }^{33}$.

Chemically modified, cell-free HBOCs, including glutaraldehyde-polymerised and PEG-conjugated Hbs, have advanced to clinical trials ${ }^{34,35}$. Nevertheless, such cell-free HBOCs showed toxicities caused by extravasation, oxidative stress, hypertension, and vasoconstriction. In contrast, the current HbVs compartmentalise a concentrated $\mathrm{Hb}$ solution in the inner aqueous phase of liposomes, analogous to erythrocytes, leading to reduced toxicities of bared $\mathrm{Hb}^{7,10,19}$. In this study, $\mathrm{HbV}$ administration had no scavenging effect on plasma $\mathrm{NO}_{\mathrm{x}}$ levels. We previously observed that $\mathrm{HbVs}$ did not cross the placental barrier ${ }^{36}$. Moreover, HbVs may be beneficial for foetuses because they are degraded by the maternal reticuloendothelial system, which is premature in the foetuses. However, the optimal strategy for improving foetal hypoxia or shock stress is an important issue that needs further research in the management of severe PPH. 


\section{Conclusion}

For severe PPH, HbVs effectively prevented lethal haemorrhagic shock in a pregnant rabbit model. These findings support that these blood substitutes may be an alternative modality for the initial treatment of severe PPH particularly in institutions with limited availability of blood products, and the role of immediate care until transportation to a secondary or tertiary facility.

\section{Disclosure of Interests}

Of the authors, H.S. is the inventor of patents related to the production and utilisation of Haemoglobin vesicles. Oher authors have declared that no conflict of interest exists. Completed disclosure of interest forms are available to view online as supporting information.

\section{Contribution to Authorship}

Conceived and designed the experiments: H.I., K.H., M.K., M.M., and K.T. Performed the experiments: H.I., K.H., M.K., and Y.Y. Analysed and interpreted the data: H.I., K.H., and M.K. Contributed reagents/ materials/ analysis tools: M.M., H.S., D.S., K.T., and M.T. Supervised: D.S. and M.T. Wrote the paper: H.I., K.H., and M.K.

\section{Details of Ethics Approval}

The experimental protocol was approved by the Institutional Review Board for the Care of Animal Subjects of the National Defense Medical College (ethical approval number: \#17032, 07/08/2017). All applicable international, national, and/or institutional guidelines for the care and use of animals were followed.

Funding. This work was supported in part by JSPS KAKENHI (grant number 19K09760 (Y.Y., M.M., K.H., M.K., and K.T.) and AMED (grant numbers 18lk14030XXh0002 and 19lk1403022h0002 (M.K. and H.S.) from Japan Agency for Medical Research Development.

\section{Acknowledgements}

We would like to thank Ms. Mio Konno for supporting this work. We also acknowledge the Editage for help with language editing of the manuscript.

\section{Supporting Information}

Additional Supporting Information may be found in the online version of this article:

Table S1. Properties of haemoglobin vesicles.

Table S2. Variables associated with bleeding during the experiment.

Table S3. Survival rates of the foetuses after haemorrhagic shock.

Figure S1. Changes in the platelet counts.

Figure S2. Changes in the levels of $\mathrm{PaO}_{2}, \mathrm{PaCO}_{2}$ and $\mathrm{HCO}_{3}$.

Figure S3. Changes in the values of activated clotting time, clot rate and plasma $\mathrm{NO}_{2}{ }^{-} / \mathrm{NO}_{3}{ }^{-}$(nitric oxide, $\mathrm{NO}_{\mathrm{x}}$ )/T0: $\mathrm{NO}_{\mathrm{x}}$.

$\mathrm{NO}$, nitric oxide; $\mathrm{T} 0: \mathrm{NO}_{\mathrm{x}}$, the value of $\mathrm{NO}_{\mathrm{x}}$ at the start of the experiment

\section{References}

1. Say L, Chou D, Gemmill A, Tuncalp O, Moller AB, Daniels J, et al. Global causes of maternal death: A WHO systematic analysis. Lancet Glob Health. 2014;2(6):e323-33

2. O'Brien KL, Shainker SA, Lockhart EL. Transfusion management of obstetric hemorrhage. Transfus Med Rev. 2018;32(4):249-55 
3. Weeks A. The prevention and treatment of postpartum haemorrhage: What do we know, and where do we go to next? BJOG. 2015;122(2):202-10

4. Committee on Practice Bulletins - Obstetrics. Practice Bulletin number 183. Practice Bulletin No. 183: Postpartum hemorrhage. Obstet Gynecol. 2017;130(4):e168-86

5. Wang Y, Han W, Pan L, Wang C, Liu Y, Hu W, et al. Impact of COVID-19 on blood centres in Zhejiang Province China. Vox Sang. 2020

6. Baron DM, Franchini M, Goobie SM, Javidroozi M, Klein AA, Lasocki S, et al. Patient blood management during the COVID-19 pandemic: A narrative review. Anaesthesia. 2020

7. Sakai H. Overview of potential clinical applications of hemoglobin vesicles (HbV) as artificial red cells, evidenced by preclinical studies of the Academic Research Consortium. J Funct Biomater. 2017;8(1):10

8. Natanson C, Kern SJ, Lurie P, Banks SM, Wolfe SM. Cell-free hemoglobin-based blood substitutes and risk of myocardial infarction and death: A meta-analysis. JAMA. 2008;299(19):2304-12

9. Chang TM. Semipermeable microcapsules. Science. 1964;146(3643):524-5

10. Sakai H, Sou K, Tsuchida E. Hemoglobin-vesicles as an artificial oxygen carrier. Methods Enzymol. 2009;465:363-84

11. Taguchi K, Miyasato M, Ujihira H, Watanabe H, Kadowaki D, Sakai H, et al. Hepatically-metabolized and -excreted artificial oxygen carrier, hemoglobin vesicles, can be safely used under conditions of hepatic impairment. Toxicol Appl Pharmacol. 2010;248(3):234-41

12. Takahashi D, Azuma H, Sakai H, Sou K, Wakita D, Abe H, et al. Phagocytosis of liposome particles by rat splenic immature monocytes makes them transiently and highly immunosuppressive in ex vivo culture conditions. J Pharmacol Exp Ther. 2011;337(1):42-9

13. Sakai H, Suzuki Y, Sou K, Kano M. Cardiopulmonary hemodynamic responses to the small injection of hemoglobin vesicles (artificial oxygen carriers) in miniature pigs. J Biomed Mater Res A.2012;100(10):266877

14. Taguchi K, Urata Y, Anraku M, Watanabe H, Kadowaki D, et al. Hemoglobin vesicles, polyethylene glycol (PEG)ylated liposomes developed as a red blood cell substitute, do not induce the accelerated blood clearance phenomenon in mice. Drug Metab Dispos. 2009;37(11):2197-203

15. Sakai H, Masada Y, Horinouchi H, Ikeda E, Sou K, Takeoka S, et al. Physiological capacity of the reticuloendothelial system for the degradation of hemoglobin vesicles (artificial oxygen carriers) after massive intravenous doses by daily repeated infusions for 14 days. J Pharmacol Exp Ther. 2004;311(3):874-84

16. Seishi Y, Horinouchi H, Sakai H, Kobayashi K. Effect of the cellular-type artificial oxygen carrier hemoglobin vesicle as a resuscitative fluid for prehospital treatment: Experiments in a rat uncontrolled hemorrhagic shock model. Shock. 2012;38(2):153-8

17. Hagisawa K, Kinoshita M, Takase B, Hashimoto K, Saitoh D, Seki S, et al. Efficacy of resuscitative transfusion with hemoglobin vesicles in the treatment of massive hemorrhage in rabbits with thrombocytopenic coagulopathy and its effect on hemostasis by platelet transfusion. Shock. 2018;50(3):324-30

18. Tokuno M, Taguchi K, Yamasaki K, Sakai H, Otagiri M. Long-term stored hemoglobin-vesicles, a cellular type of hemoglobin-based oxygen carrier, has resuscitative effects comparable to that for fresh red blood cells in a rat model with massive hemorrhage without post-transfusion lung injury. PLOS ONE. 2016;11(10):e0165557

19. Sakai H, Sou K, Horinouchi H, Kobayashi K, Tsuchida E. Haemoglobin-vesicles as artificial oxygen carriers: Present situation and future visions. J Intern Med. 2008;263(1):4-15 
20. Waters JH. Role of the massive transfusion protocol in the management of haemorrhagic shock. Br J Anaesth. 2014;113(Suppl 2):ii3-8

21. Yu YH, Gong SP, Sheng C, Zhao KS, Lodato RF, Wang CH. Increased survival with hypotensive resuscitation in a rabbit model of uncontrolled hemorrhagic shock in pregnancy. Resuscitation.2009;80(12):1424-30

22. Kilkenny C, Browne WJ, Cuthill IC, Emerson M, Altman DG. Improving bioscience research reporting: The ARRIVE Guidelines for Reporting Animal Research. PLOS Biol. 2010;8(6):e1000412

23. Hagisawa K, Kinoshita M, Takikawa M, Takeoka S, Saitoh D, Seki S, et al. Combination therapy using fibrinogen $\gamma$-chain peptide-coated, ADP-encapsulated liposomes and hemoglobin vesicles for trauma-induced massive hemorrhage in thrombocytopenic rabbits. Transfusion.2019;59(10):3186-96

24. Taguchi K, Watanabe H. A fourteen-day observation and pharmacokinetic evaluation after a massive intravenous infusion of hemoglobin-vesicles (artificial oxygen carriers) in cynomolgus monkeys. J Drug Metab Toxicol. 2012;3(4):128

25. Kawaguchi R, Matsumoto K, Akira S, Ishitani K, Iwasaku K, Ueda Y, et al. Guidelines for office gynecology in Japan: Japan Society of Obstetrics and Gynecology (JSOG) and Japan Association of Obstetricians and Gynecologists (JAOG) 2017 edition. J Obstet Gynaecol Res. 2019. Japan Society of Obstetrics and Gynecology;45(4):766-86

26. Diehl KH, Hull R, Morton D, Pfister R, Rabemampianina Y, Smith D, et al. A good practice guide to the administration of substances and removal of blood, including routes and volumes. J Appl Toxicol. 2001;21(1):15-23

27. Cannon JW. Hemorrhagic shock. N Engl J Med. 2018;378(4):370-9

28. Faul F, Erdfelder E, Lang AG, Buchner AG. G*Power 3: A flexible statistical power analysis program for the social, behavioral, and biomedical sciences. Behav Res Methods. 2007;39(2):175-91

29. Barroso J, Osborne B, Teramura G, Pellham E, Fitzpatrick M, Biehl R, et al. Safety evaluation of a lyophilized platelet-derived hemostatic product. Transfusion.2018;58(12):2969-77

30. Prick BW, Jansen AJ, Steegers EA, Hop WC, Essink-Bot ML, Uyl-de Groot CA, et al. Transfusion policy after severe postpartum haemorrhage: a randomised non-inferiority trial. BJOG. 2014;121(8):1005-14.

31. Chessman J, Patterson J, Nippita T, Drayton B, Ford J. Haemoglobin concentration following postpartum haemorrhage and the association between blood transfusion and breastfeeding: a retrospective cohort study. BMC Res Notes. 2018;11(1):686.

32. Moon PF, Bliss SP, Posner LP, Erb HN, Nathanielsz PW. Fetal oxygen content is restored after maternal hemorrhage and fluid replacement with polymerized bovine hemoglobin, but not with hetastarch, in pregnant sheep. Anesth Analg. 2001;93(1):142-50.

33. Wigger O, Bloechlinger S, Berger D, Häner J, Zanchin T, Windecker S, et al. Baseline serum bicarbonate levels independently predict short-term mortality in critically ill patients with ischaemic cardiogenic shock. Eur Heart J Acute Cardiovasc Care.2018;7(1):45-52

34. Olofsson C, Ahl T, Johansson T, Larsson S, Nellgård P, Ponzer S, et al. A multicenter clinical study of the safety and activity of maleimide-polyethylene glycol-modified hemoglobin (Hemospan) in patients undergoing major orthopedic surgery. Anesthesiology.2006;105(6):1153-63

35. Jahr JS, Mackenzie C, Pearce LB, Pitman A, Greenburg AG. HBOC-201 as an alternative to blood transfusion: Efficacy and safety evaluation in a multicenter phase III trial in elective orthopedic surgery. J Trauma. 2008;64(6):1484-97

36. Li H, Ohta H, Tahara Y, Nakamura S, Taguchi K, Nakagawa M, et al. Artificial oxygen carriers rescue placental hypoxia and improve fetal development in the rat pre-eclampsia model [sci. rep. :15271]. Sci Rep. 


\section{Figure Legends}

Figure 1. Surgical procedures and Experimental protocol.

(A) Rabbits underwent caesarean section to deliver foetuses in the right side of the bicornate uterus. (B) After closing the incision in the uterus, uncontrolled haemorrhage was induced by transecting the right uterine artery and concomitant vein. (C) Pregnant rabbits underwent caesarean section, and uncontrolled haemorrhage was induced to develop severe postpartum haemorrhage (PPH). First, all rabbits were administered $6 \%$ HES for initial treatment. After developing severe $\mathrm{PPH}$, rabbits received isovolumic fluid resuscitation with an equivalent volume of haemorrhage every $5 \mathrm{~min}$. Resuscitative administration regimens included the following: RBCs with PPP (vol/vol=1:1, $n=8)$, $6 \%$ HES $(n=7)$, or HbVs with $25 \%$ human serum albumin $(\mathrm{vol} / \mathrm{vol}=4: 1, n=10)$. After $60 \mathrm{~min}$ from the start of bleeding or when the haemorrhage volume reached 200 $\mathrm{mL}$, we performed surgical hemostasis.

CS, caesarean section.

Figure 2. Haemodynamic changes and Suvival curves of all three groups.

(A) Unlike $\mathrm{HbV}$ and RBC/PPP group, the mean arterial pressures (MAP) were gradually decreased in HES group, whereas MAP in $\mathrm{HbV}$ and $\mathrm{RBC} / \mathrm{PPP}$ group was maintained over $40 \mathrm{mmHg}$. (B) Shock index was gradually increased in all groups, but there were no significant differences throughout the experiment. (C) Survival of $\mathrm{HbV}$ group was significantly better than that of HES group $(p<0.01)$, whereas it was significantly worse than that of RBC/PPP group $(p=0.01)$.

Values represent the mean \pm SD. Statistical comparisons between two groups were performed using Student's t test. One-way ANOVA and post hoc tests where appropriate were used to identify significant mean differences between three groups. ${ }^{*} p<0.05$ indicate significant difference. Survival curves were generated using the Kaplan-Meier method and compared using the log-rank test.

$+p<0.05$, the prognosis of RBC/PPP group was significantly different from that of the other groups.

$++p<0.05$, the prognosis of $\mathrm{HbV}$ group was significantly different from that of the HES group.

Figure 3. Changes in haematologic variables and blood gas levels.

(A) At the end of the experiment, the $\mathrm{Hb}$ concentration was maintained over $6.0 \mathrm{~g} / \mathrm{dL}$ in $\mathrm{RBC} / \mathrm{PPP}$ and $\mathrm{HbV}$ groups, whereas it decreased under $2.0 \mathrm{~g} / \mathrm{dL}$ in HES group. (B) The haematocrit was similarly decreased in both $\mathrm{HbV}$ and HES groups, but not in RBC/PPP group. (C) The $\mathrm{pH}$ levels in HES group were significantly lower than those in the other groups after $30 \mathrm{~min}$. (D) There were no significant differences in the base excess levels among all groups throughout the experiment. (E) At the end of the experiment, the lactate acid levels were significantly higher in HES group than in the other groups. (F) The $\mathrm{CtO}_{2}$ level was decreased in all groups until $30 \mathrm{~min}$, but it was maintained above approximately $7.0 \mathrm{vol} \%$ beyond $30 \mathrm{~min}$ in $\mathrm{RBC} / \mathrm{PPP}$ and HbV groups.

$\mathrm{CtO}_{2}$, arterial oxygen content.

Values represent the mean +- SD. Between-group comparisons were performed using Student's t test. Oneway ANOVA and post hoc testing where appropriate were used to identify significant mean differences between the three groups.

${ }^{*} p<0.05$, value significantly different from other groups.

Figure 4. Changes in coagulation variables.

(A) The values of plasma fibrinogen in RBC/PPP group was maintained over $110 \mathrm{mg} / \mathrm{dL}$ even at the end of the experiment. (B) The values of AT III in HbV and HES groups were significantly decreased than those in RBC/PPP group at $45 \mathrm{~min}$ and at the end of the experiment. (C) The values of PT in HbV and HES 
groups were significantly longer than that in RBC/PPP group at the end of the experiment. (D) The values of APTT after 30 min was set as the reference value because the value over 75 sec could not be measured in the current analysis.

PT, prothrombin time; APTT, activated partial thromboplastin time.

Values represent the mean +- SD. Statistical comparisons between two groups were performed using Student's $\mathrm{t}$ test. One-way ANOVA and post hoc testing where appropriate were used to identify significant mean differences between the three groups.

${ }^{*} p<0.05$ indicates significant difference.

** At the end of the experiments, the APTT levels were unmeasurable in the HbV and HES groups.

Fig. 1
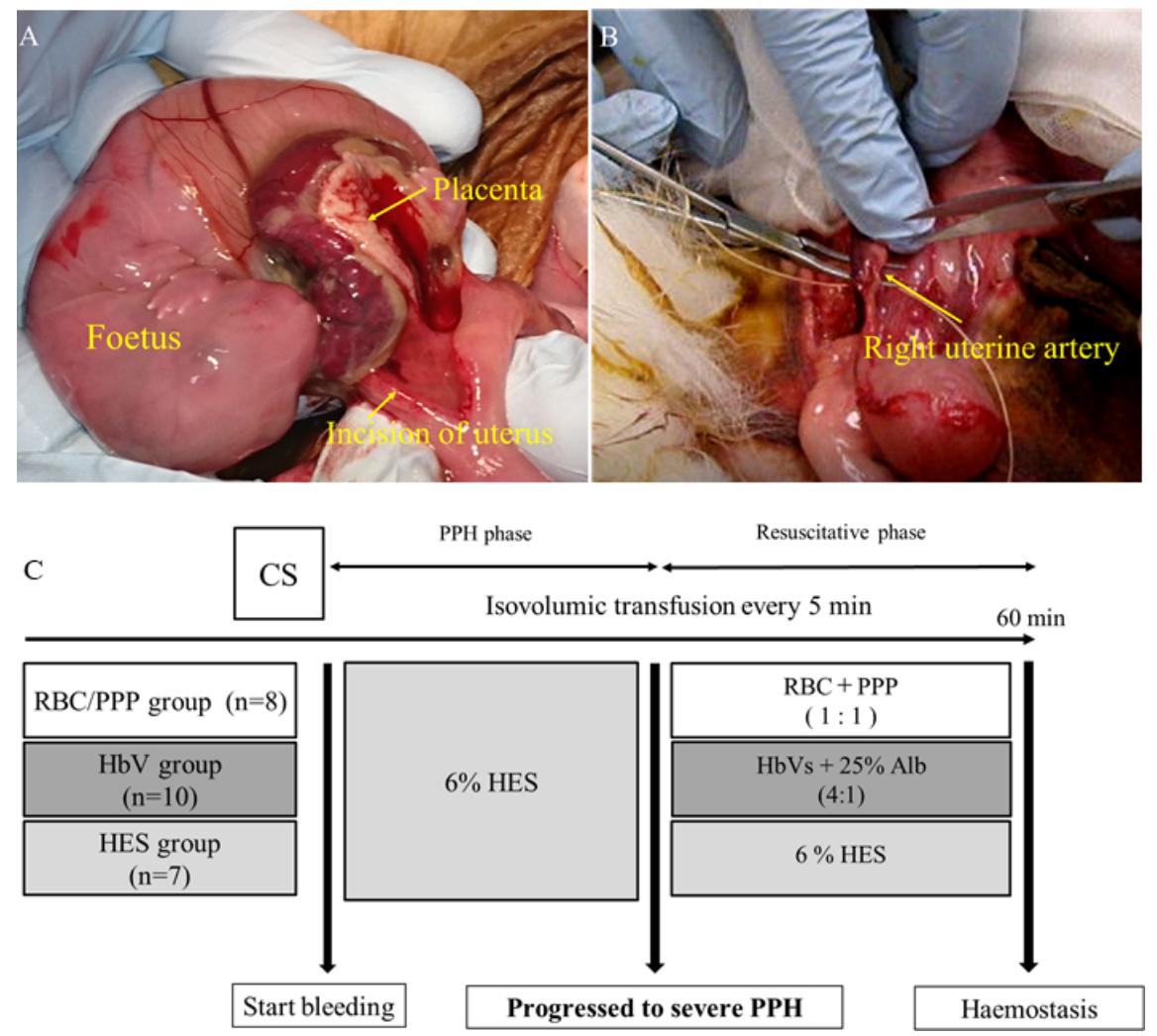
Fig. 2
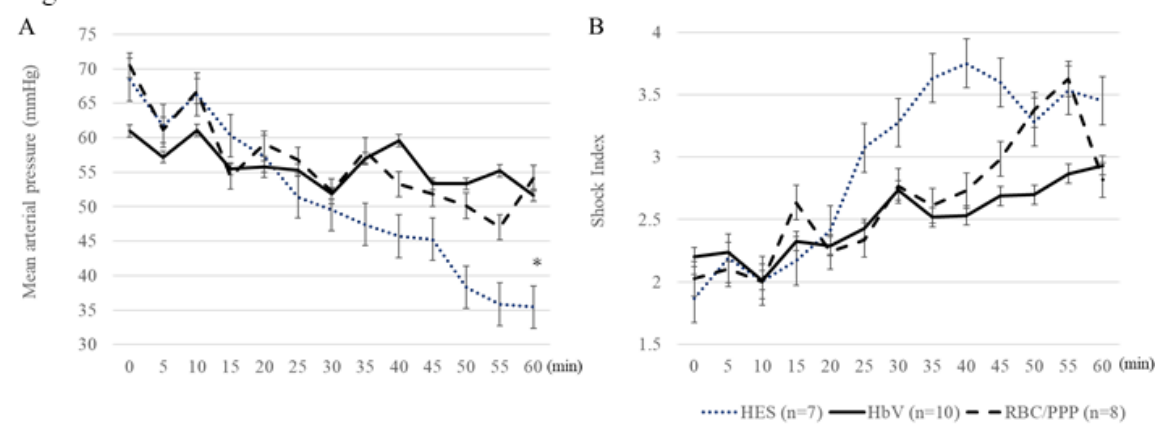

C

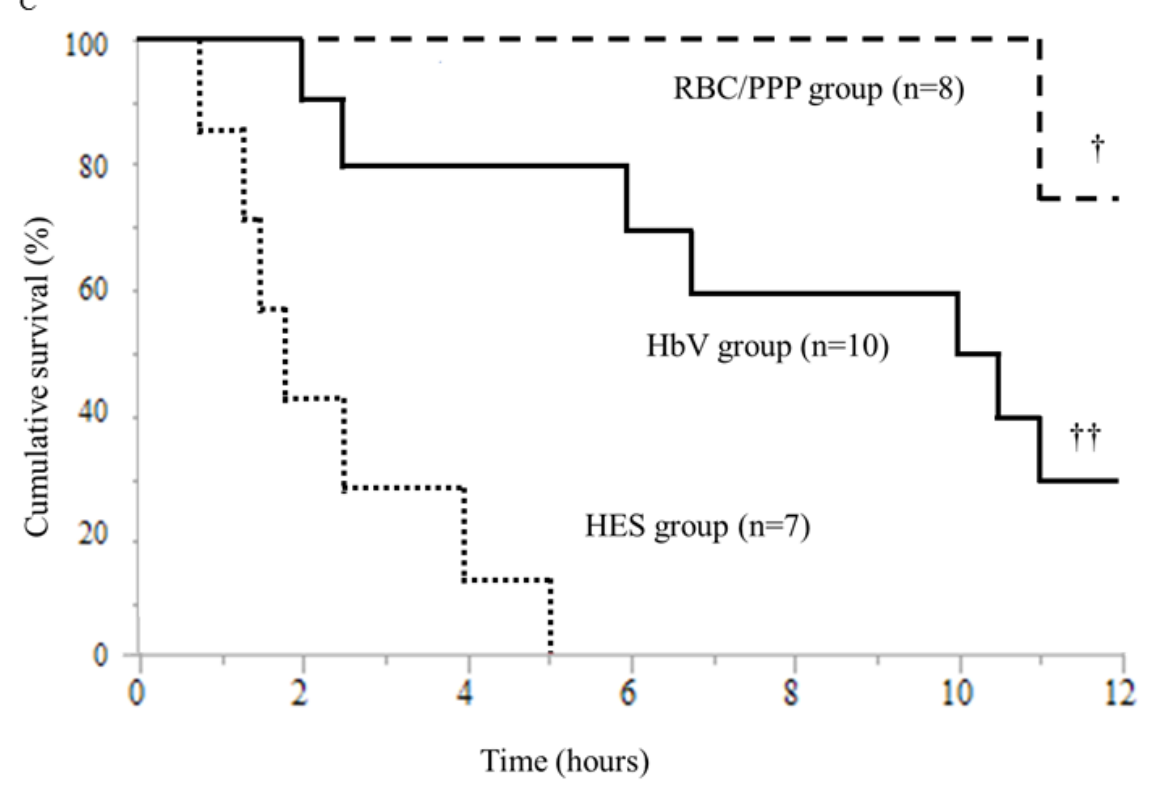


Fig. 3
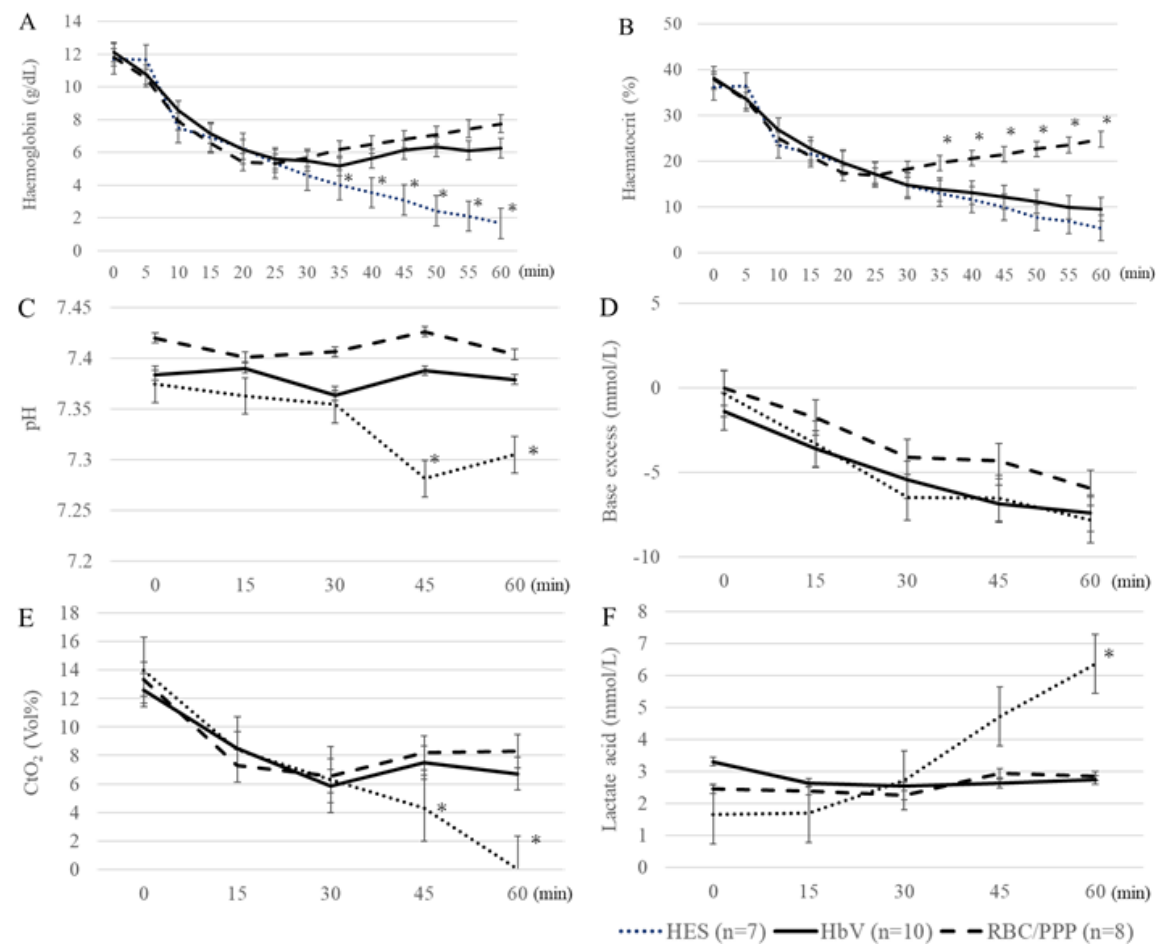

Fig. 4
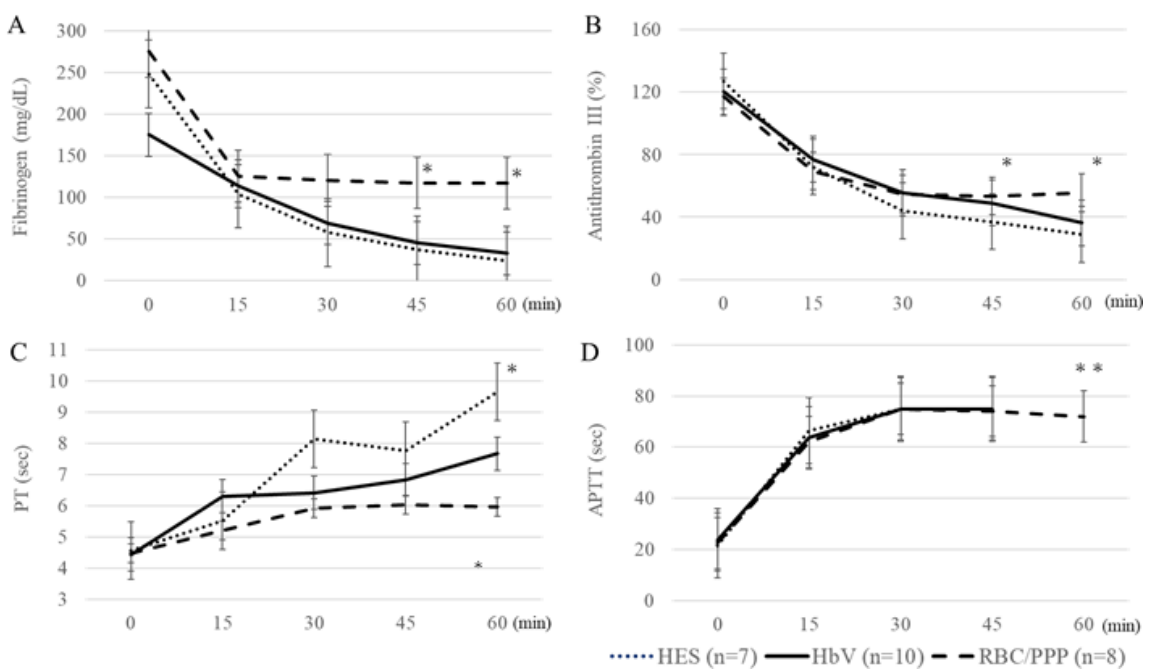